\title{
The visual-landscape analysis during the integration of high-rise buildings within the historic urban environment
}

\author{
Vera A. Akristiniy ${ }^{1, *}$ and Elena A. Dikova ${ }^{1}$ \\ ${ }^{1}$ Moscow State University of Civil Engineering, Yaroslavskoe shosse, 26, Moscow, 129337, Russia
}

\begin{abstract}
The article is devoted to one of the types of urban planning studies - the visual-landscape analysis during the integration of high-rise buildings within the historic urban environment for the purposes of providing pre-design and design studies in terms of preserving the historical urban environment and the implementation of the reconstructional resource of the area. In the article formed and systematized the stages and methods of conducting the visual-landscape analysis taking into account the influence of high-rise buildings on objects of cultural heritage and valuable historical buildings of the city. Practical application of the visual-landscape analysis provides an opportunity to assess the influence of hypothetical location of high-rise buildings on the perception of a historically developed environment and optimal building parameters. The contents of the main stages in the conduct of the visual - landscape analysis and their key aspects, concerning the construction of predicted zones of visibility of the significant historically valuable urban development objects and hypothetically planned of the high-rise buildings are revealed. The obtained data are oriented to the successive development of the planning and typological structure of the city territory and preservation of the compositional influence of valuable fragments of the historical environment in the structure of the urban landscape. On their basis, an information database is formed to determine the permissible urban development parameters of the high-rise buildings for the preservation of the compositional integrity of the urban area.
\end{abstract}

\section{Introduction}

Introduction of the conduct of the visual-landscape analysis practice of high-rise buildings in the system of preparation of pre-project documentation allows not only assessing the influence of hypothetically existing buildings on the perception of historically valuable objects of the urban environment. It also allows assessing the possible parameters of highrise construction in the conditions of ensuring the continuity of the urban landscape and providing a unified urban policy $[1,3]$.

The visual-landscape analysis is one of the tools of urban forecasting, that allows specifying the regulatory requirements and restrictions established for a particular territory.

\footnotetext{
*Corresponding author: $\underline{7824666 @ \text { mail.ru }}$
} 
Applying the visual-landscape analysis methods has received official status in Moscow as a mandatory part of the preparation of pre-project and project documentation within the framework of the overall urban policy. The regulatory restrictions of a particular territory are directly dependent on the protection zones in which it is included, taking into account the location in the city structure, the level of historical and cultural potential, the degree of the traditional urban environment preservation, the city-forming importance and other valuable characteristics of cultural heritage objects [2].

The maintenance regimes for all zones of protection provides the optimal perception of historical and cultural monuments in the structure of the urban environment, preservation of valuable historical panoramas and types of urban landscape by adjusting the height parameters of the designed buildings in terms of the city-forming objects valuable visibility.

Methods of the visual-landscape analysis can be used to solve a variety of problems: urban planning forecast of a general nature, the output of permissible height constrictions for a particular object, computer modeling of various variants of the design solution in the system of the urban environment, a visual perception review of the designed object, revealing of the inconsistency of the realized high-rise parameters of the object to the approved project etc $[4,7]$.

The recommended range of height, density and other parameters of the reconstruction and new construction of objects in the historical center of Moscow is determined based on general regulatory requirements and urban development restrictions of territory. Clarification of the permissible volumetric and planning characteristics of the designed buildings to be placed in the system of city panoramas, as well as compositionally interconnected with the monuments of history and culture, valuable fragments of the existing urban-planning environment, is carried out by taking into account features of the space-planning organization of the urban landscape fragment under consideration, historical and cultural studies and conclusions of the visual-landscape analysis [5].

Thus, the application of visual analysis does not contradict the perspective development of town planning regulations and allows to quickly identify inadmissible in terms of protecting cultural heritage or compositionally controversial project proposals, in the absence or inadequate elaboration of documents. The study was conducted in order to identify sectors of the interaction of designed buildings and structures with cultural heritage and analyzing peculiar overview properties of the object in the structure of urban spaces, to account for the formation of composite solutions of the designed building in the future $[6,8]$.

\section{The method of visual-landscape analysis}

Visual landscape analysis implementation based on field investigations of the territory, analysis of photo fixation materials, as well as expert evaluation of the urban development situation.

The main stages of the visual-landscape analysis shown in Fig.1 [9]. 
Formation of the historical inquiry of the studied territory

Designation of historically valuable urban-planning objects and their territories

The composition of predicted visibility zones of significant urban-planning objects

Computer modeling of the visibility rays of a historically valuable town-planning object

The composition of predicted visibility zones of a projected building

Computer modeling of the visibility rays of a projected building

Selection of the control visual perception directions

Determination of existing compositional and spatial types of urban-planning architecture

Photo modeling of projected objects

Graphical combination of the projected object with materials of field photographic fixation

Expert evaluation of urban planning situation

Urban-planning characteristics of the territory under consideration

Fig.1. Contents of the main stages of visual-landscape analysis

The convincingness of the visual-landscape analysis conclusions to a certain extent depends on the exposition methods of the resulting visual sequence. The illustrative materials have a discrete character and give a fragmentary picture of the future compositional role of the new volume in the structure of the urban landscape.

New technological possibilities of materials submission allow estimating the forecasted development of the urban-planning situation by analyzing video materials. The dynamic perception of the new construction object contributes to the maximum approximation to reality, ensuring a continuous nature of the survey, and demonstrates exhaustive information about the town-planning significance of a particular type of object disclosure. The application of video makes more evident the expert evaluation of the control visual perception directions, because of which it proposed to correct the height parameters of the object [13].

The use of new visual analysis methods is promising not only for the purpose of determining high-rise restrictions in zones of interaction between new construction sites with historical and cultural heritage, but also in solving complex urban problems related to the location and expected interaction of a number of projected complexes, including new areas of the city.

The tasks of visual analysis, primarily designed to ensure the optimal perception of cultural heritage sites, also include the development of recommendations for the preservation and successive development of aesthetically expressive fragments of the urban landscape.

The documentation presented in the visual-landscape analysis differentiated according to three main sections (containing text, graphic and illustrative materials) [11]:

1. urban-planning characteristics of the territory under consideration;

2. analysis of the compositional interaction of the projected object with a valuable urbanplanning environment;

3. conclusions of the visual-landscape analysis.

The urban-planning characteristic of the territory contains a generalized analysis of the most important features (geomorphological, composition and planning, scale-typological) of the valuable urban landscape fragment, as well as existing requirements and limitations of 
urban development of the territory, established by applicable legislative and regulatory documents. Geomorphological features include the characteristics of the territory landscape under study [12].The compositional-planning features of the territory include aspects of the urban-planning space that determine the interconnection of all its elements, which as a result create completeness and its integrity. The purpose of compositional and planning characteristics is to bring to unity the functional, technical, economic, ecological, and aesthetic requirements of the territory [14].

Within the framework of the expert evaluation of the urban-planning situation, the territory under study is analyzed on the basis of zoning schemes for the Master Plan of Moscow until 2025 (functional zoning, analysis of the reorganization areas and development zones, protection zones) [10].

The analysis of the compositional interaction of the projected object with a valuable urban-planning environment is carried out in order to identify valuable urban panoramas and types of the study area and their compositional features, determine the conditions for visual perception of particularly significant urban-planning dominants and valuable fragments of traditional buildings, as well as forecast the permissible development of compositional and visual characteristics of the territory.

Based on the materials of this section, the conditions for the correspondence of the volume-planning, including the height and compositional parameters of the projected complex to the characteristics of a valuable urban landscape are revealed (Fig. 2) [15].

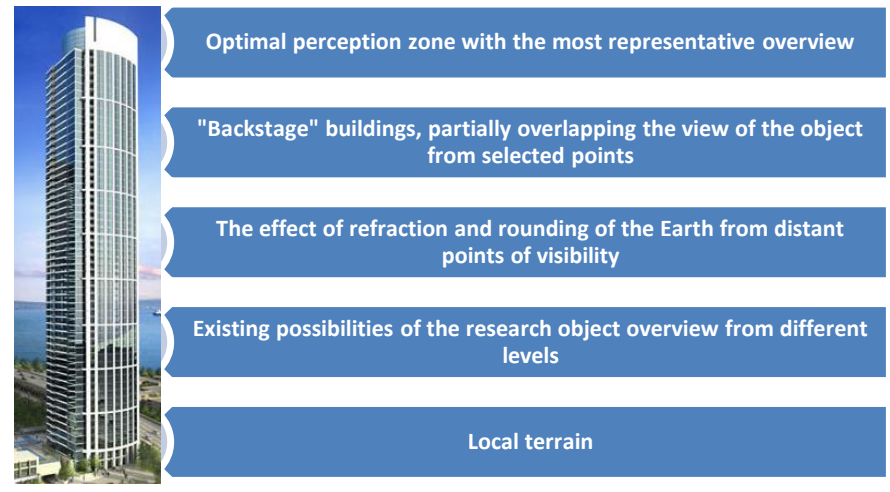

Fig.2. Scheme of the method for recording conditional visual communication lines between the viewer and the studied object

\section{Practical results}

The visual-landscape analysis carried out according to the presented method when integrating the high-rise building of the business center into the territory of cultural heritage objects in Moscow revealed the permissible parameters of the space-planning decisions of the projected object. According to the analysis of the studied territory of cultural heritage objects (Fig. 3), the visibility pan of the most significant cultural heritage objects (Fig. 4) and the projected high-rise buildings predicted visibility zones (Fig. 5) are determined [10]. 


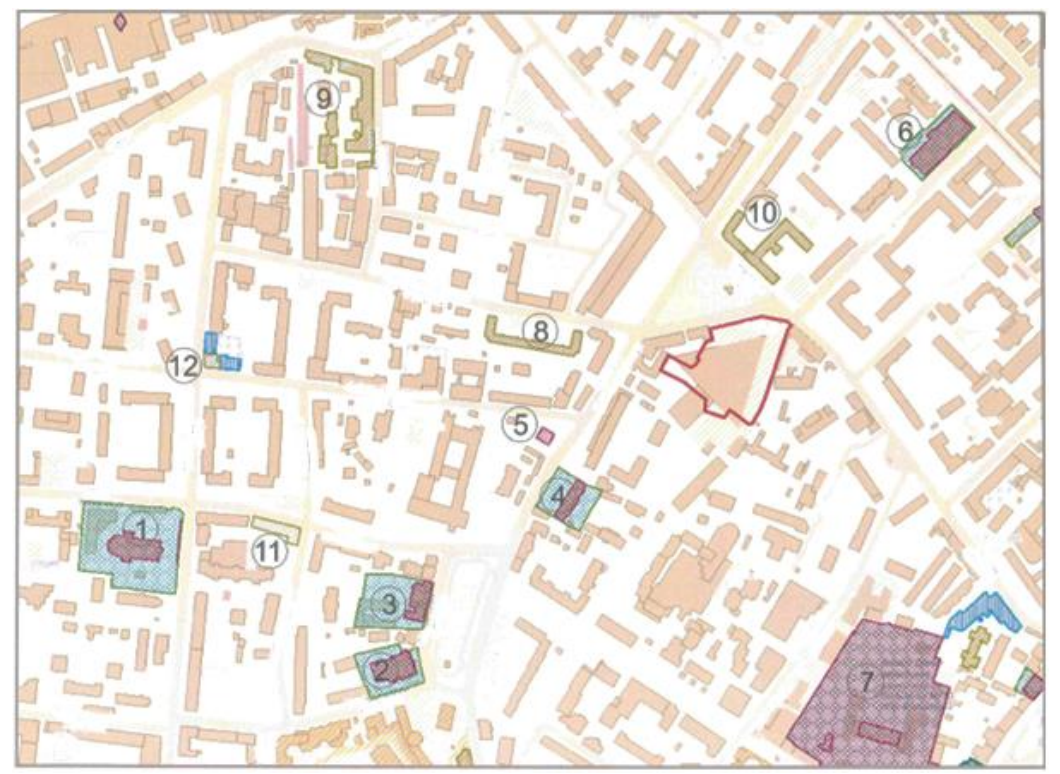

Fig.3. Scheme of cultural heritage objects with the location designation of the high-rise object in the studied territory at the address:1/1Tishinskaya Ploshchad', Moscow,(1- Cathedral of the Immaculate Conception, 1910-1911, architect Bogdanovich F.F.; 2- Temple of the Great Martyr George the Victorious, 1788 - 1807, 1870s, 1890s; 3 - Residential house, the end of the XIX century; 4- Residential house, 1937, architect Diederichs Yu.F.; 5 - The house in which in 1902 - 1903 lived A.L. Nikolayevich; 6- Central house of cinema, late XIX - early XX centuries, architect Stamo E.M.; 7 - Garden of the Filatovskaya children's hospital; 8 - Dwelling house, 1929-1930; 9 - Firsanov's home for widows and orphans, 1883; 10 - Dwelling house, 1928, architect P.A. Andreev; 11 - Profitable house, 1905, architect E.K. Nirnsee, 1912, architect Gashinsky; 12 - Profitable house, 1908 - 1911, architect V.M. Uglichinin).

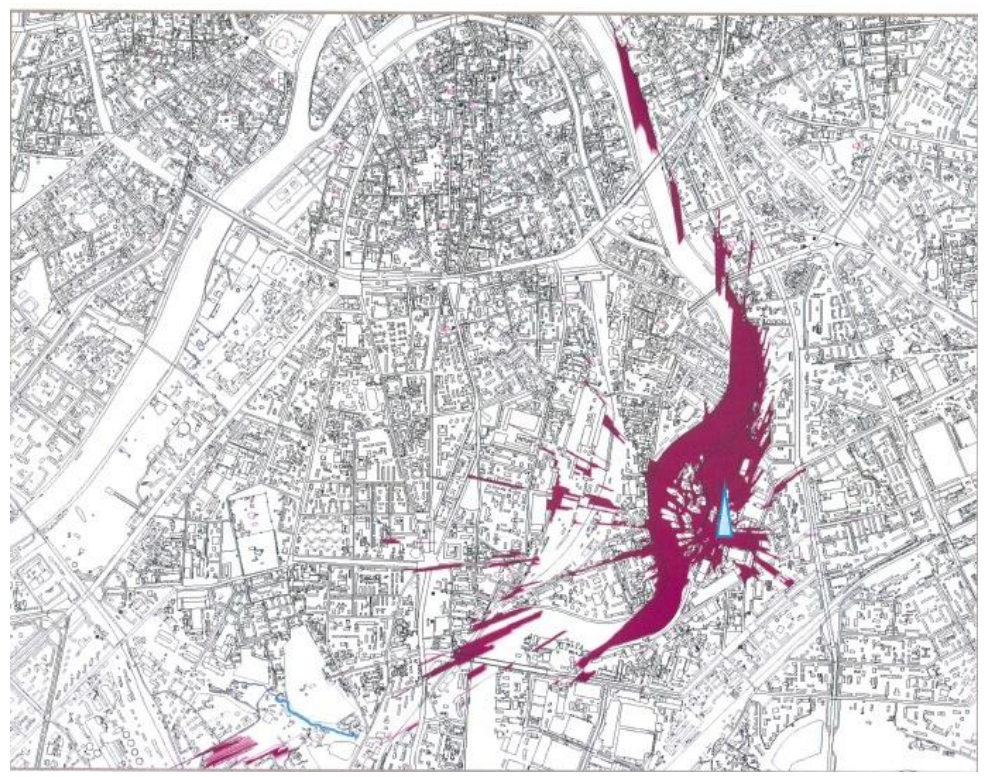

Fig.4. The visibility pan of the cultural heritage object- Simonov Monastery Ensemble (the cultural heritage object of federal significance). Address: Moscow, st. East, possession 4. 


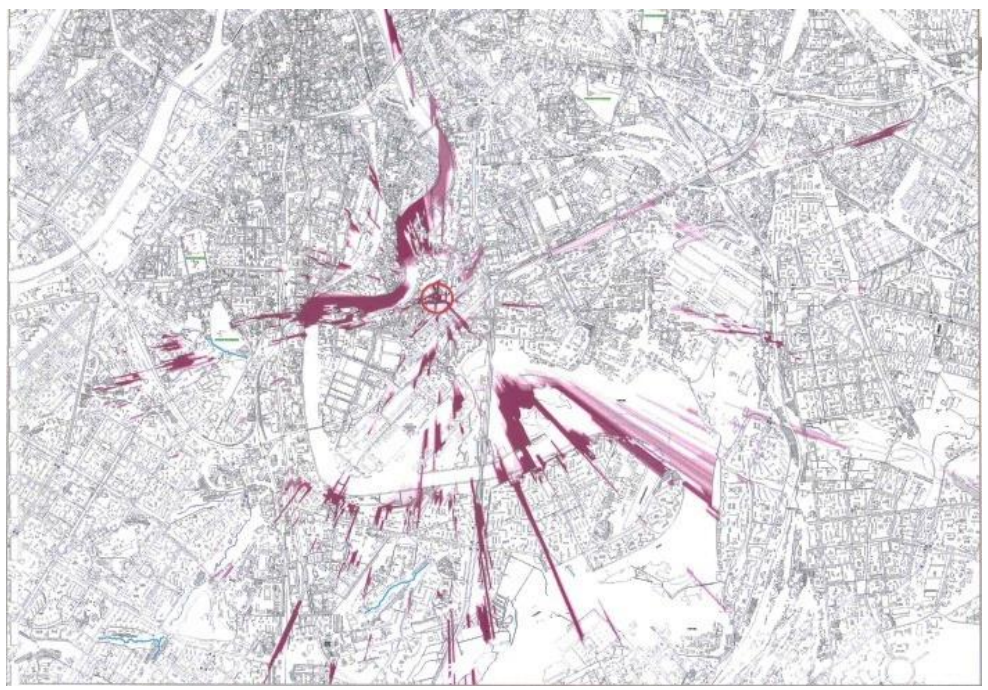

Fig.5. Predicted visibility zones of the high-rise building

At the stage of expert appraisal of the urban-planning situation, the main task of visuallandscape analysis is to verify the urban planning (volume-planning) characteristics and determine the permissible height parameters of the object under study [16,19].

In order to determine the permissible range of high-rise building parameters and to perform the visual-landscape studies, a 3D model with maximum height and volume parameters are presented (Fig. 6,7).

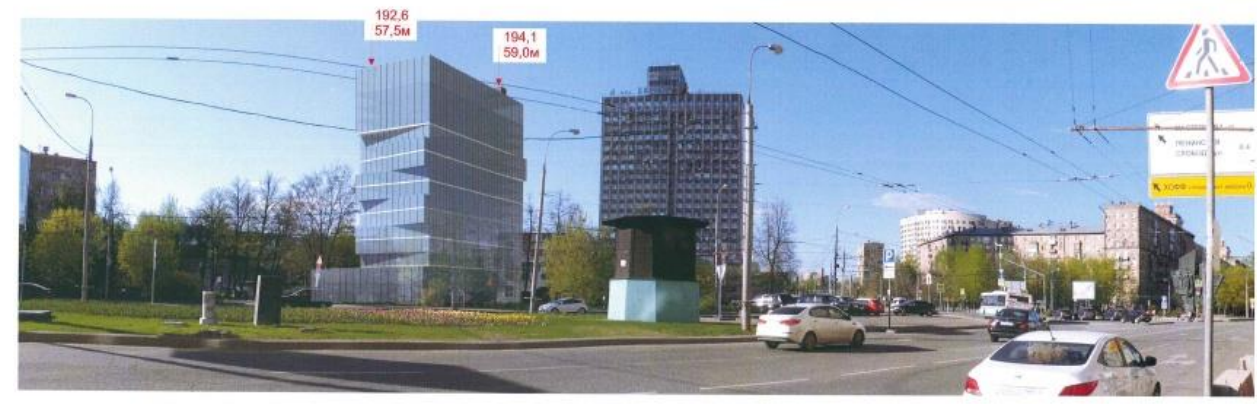

Fig.6. Photo modeling of capital construction object with an indication of the possible parameters of space-planning solutions. Moscow, 3rd Avtozavodskaya passage, possession 13.

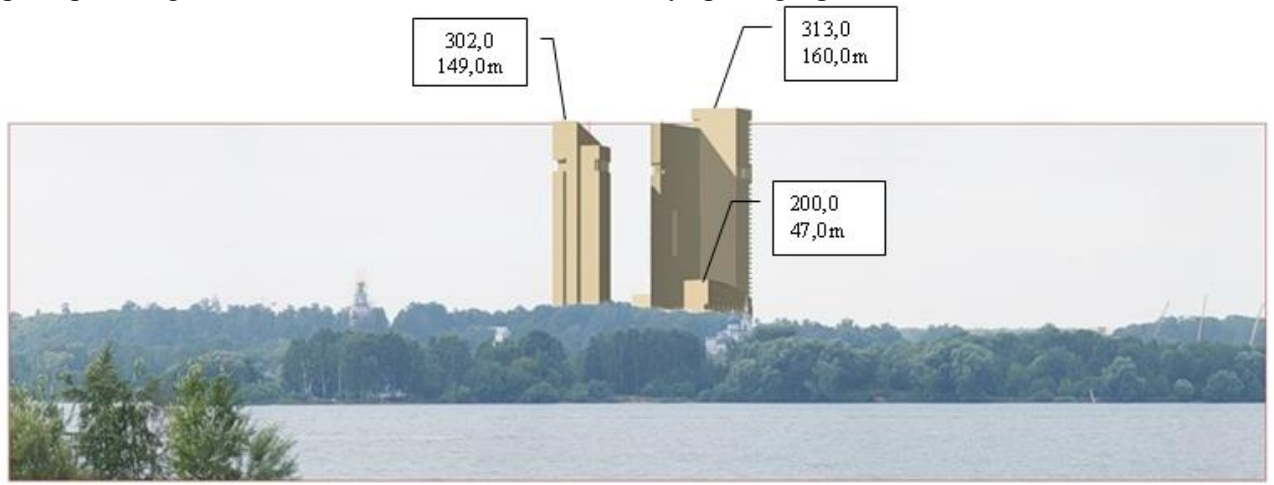

Fig.7. Photo modeling reflecting the influence of high-rise building on the perception of cultural heritage objects 
Despite the above advantages, visual analysis is not the only factor determining the direction of the urban landscape development and the citywide panoramas formation principles. It is known that the results of the visual perception examination, with the determined degree of the object's compliance of the urban environment, are not always taken into account when making decisions on architectural councils, as well as the concept of "urban error" does not have an unambiguous interpretation, clear evaluation criteria and is subjective in its nature. Proceeding from this, determined the high probability of urbanplanning errors appearance, which can be significantly reduced by the introduction of the visual-landscape analysis practice. Specific examples of the visual-landscape analysis application, as well as the consequences caused by non-compliance with the recommended height restrictions, allow us to express confidence that the positive vector prevails in the evaluation of this method [18].

Having analyzed the materials of the Committee for the state preservation of historical and cultural monuments (KGIOP) "Visual-Landscape analysis of the "Okhta Center" [17] complex high-rise building influence on the silhouette of the historical center of St. Petersburg" the ambiguity of the examination conclusions can be confirmed. An analysis of the visual perception estimated from 25 points of the city center showed that the construction of the proposed high-rise building "does not affect" only 3 of the 25 selected positions, which cannot be considered safe for the historical prospects of St. Petersburg. However, the very fact of carrying out such a study made it possible to use fragments of examination materials to justify the possibility of erecting a high-rise object in the historically developed low-rise zone based on partial presentation of materials. It is a question of the discrepancy between the space-planning parameters of the designed high-rise building for regulatory requirements and the restrictions of the territory urban development.

a)

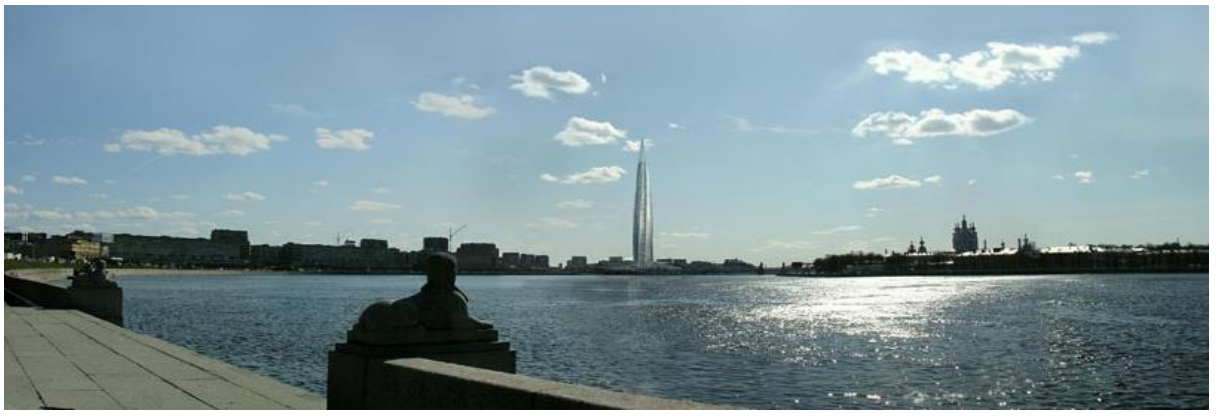

b)

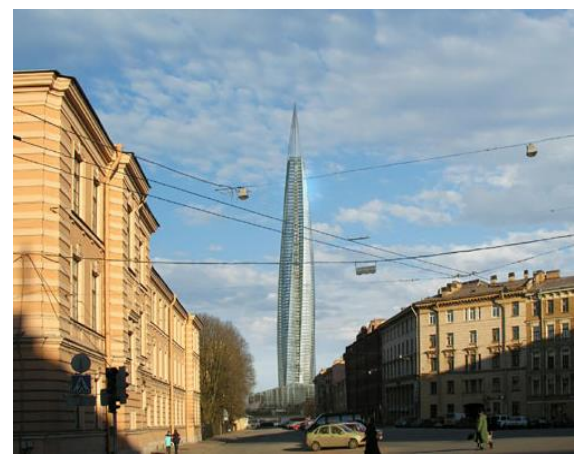

c)

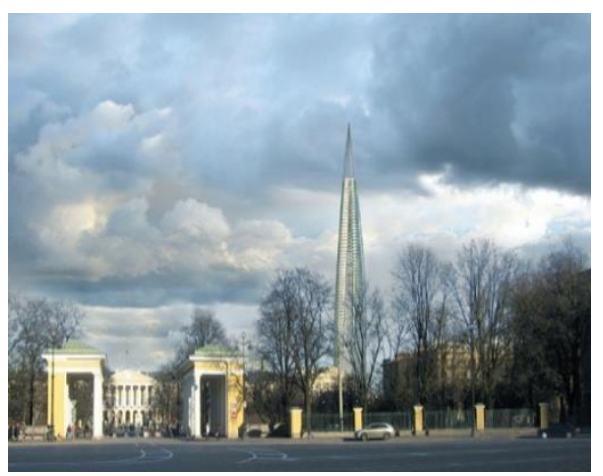

Fig.8. High-rise "Okhta Center" building, Saint Petersburg (a - view from the Sverdlovskaya embankment, $\mathrm{b}$ - view from Smolny prospect, $\mathrm{c}$ - view from the Proletarian dictatorship square) 
The results of visual-landscape analysis recommended for accounting in the framework of urban-planning activity are oriented to the successive development of the spatial planning and typological structure of the territory, and the preservation of the compositional influence of valuable fragments of the historical environment in the urban landscape structure. Information obtained in the context of visual-landscape analysis is the basis for determining the urban-planning characteristics of the projected object and the realization of the reconstructive resource of the territory $[7,10]$.

Visual-landscape analysis of the projected object carried out within the development framework of justifying materials for consideration of the further design issue in the selected territory. Conclusions of visual-landscape analysis considered when preparing project documentation for new construction sites, reconstruction of existing buildings and taken into account when reviewing and agreeing on project documentation.

\section{Discussion}

It is necessary to emphasize that conclusions and recommendations of visual-landscape analysis are not proposed to be absolutized. The degree of rigor and level of validity of the high-rise restrictions depends on many factors, such as the concretization of the urbanplanning situation, the researcher's forecast about the ways of possible development of the urban landscape, previously approved project solutions.

One of the most significant problems directly related to the criteria for justifying highrise constraints in the conduct of visual-landscape analysis is the anticipated development of composition-scale and silhouette characteristics of the urban environment. Gradual distribution of hyper-scale building complexes will lead to structural changes in citywide panoramas and the emergence of new conditions for the perception of the central part of the city. This problem requires joint development of conceptual ideas about the ways of possible urban landscape character development [14,20].

At the same time, adjusting the height parameters of the object based on the conclusions of visual-landscape analysis, optimal for the traditional urban environment, can lead to an undesirable change in the proportional structure, a decrease in the stylistic and imaginative expressiveness of the projected building, which means to promote the adoption of averaged decisions.

In this connection, it is necessary to distinguish that the recommendations made by experts in the field of visual-landscape analysis cannot be considered only true, but should be taken into account when considering project documentation on architectural boards.

In this respect, the preliminary height constraints at the pre-designed stage can be adjusted for the specific design solution. Such an approach is methodologically justified in those cases when the height constraints caused by the need to observe the compositional-spatial correspondence of the object to the structure of citywide panoramas [21].

Recommendations for preserving the composite unity of particularly valuable cityforming objects in the urban landscape structure have specific indicators, expressed in permissible absolute elevations. Conclusions of visual and landscape analysis are subject to mandatory compliance in those cases where the projected volume causes distortion of the historical and cultural monuments perception caused by a reduction in visual disclosure or a violation of background characteristics $[3,21]$. The regulation of the height parameters of the designed buildings in order to ensure the composition-scale compliance of the new volume with the valuable urban-planning environment is of an advisory nature. Expressiveness, quality and persuasiveness of the architectural solution of the object can substantiate the expediency of correcting the high-rise restrictions established in the framework of visuallandscape studies. 


\section{Conclusions}

The current city regulating mechanisms combine data from general regulatory documents with detailed visual-landscape studies within the confines of a developed system of procedural approvals and examinations.

Despite the excessive construction activity, rapidly changing the face of the city, Moscow still retains especially valuable, in the true sense, peculiar fragments of the urban landscape with a high concentration of historical and cultural monuments. In connection with the fact that one of the main problems of urban-planning protection in the capital is the active reduction of the number of authentic cultural heritage objects, it is required to rethink such design and construction practice and take adequate measures corresponding to the status of the historic city $[2,10]$. The rehabilitation of especially valuable territories, the low level of the reconstructive resource of which compensated by the high historical and cultural significance, must be implemented within the confines of strict urban planning regulations with the predominant use of conservation methods and methods of rehabilitation.

Less valuable fragments in the historical and cultural sense of the city, including in the central part of it, may have increased the city-forming potential, allowing more free development without compromising cultural heritage. Forecasting of urban-planning activity using visual-landscape analysis methods, topical and in peripheral territories, allows to reveal the maximum reconstructive resource of a given site, and also to exclude serious composite miscalculations, by establishing the degree of conformity of the volume-planning solution and the high-rise parameters of the projected object in the structure of city panoramas $[12,20]$.

\section{References}

1. L. Dupont, K. Ooms, M. Antrop, V. V. Etvelde, Landscape and Urban Planning 167, 325-338 (2017)

2. S. Pardo-García, M. Mérida-Rodríguez, Computers, Environment and Urban Systems 61(A), 56-65 (2017)

3. R. Wang, J. Zhao, Z. Liu, Urban Forestry \& Urban Greening20, 210-217 (2016)

4. H. Jang, J. Kang, Energy and Buildings 158(1), 656-667 (2018)

5. J.M. Lee, W. W. Braham, Ecological Modelling 363(10), 157-171 (2017)

6. F. Peng, M. S. Wong, H. C. Ho, J. Nichol, P. W. Chan, Building and Environment 123, 649-660 (2017)

7. M. M. Shanoer, F. M. Abed, The Egyptian Journal of Remote Sensing and Space Science 2, (2017)

8. J. de Beer, F. Boogaard, Procedia Engineering 209, 34-41 (2017)

9. V. Kutut, Procedia Engineering 208, 69-75 (2017)

10. V.A. Akristiniy, E.A. Dikova, Real Estate: Economics 3, 37-45 (2017)

11. M. Peniüa, Procedia Engineering 117,883-890 (2015)

12. A.A. Kuzmichev, V.F. Loboyko, Procedia Engineering 150,2095-2101 (2016)

13. V.A. Stolbova, L.I. Pavlova, Real Estate: Economics 2, 76-84 (2015)

14. M.Kisternaya, V.Kozlov, Journal of Cultural Heritage 13, 74-78(2012)

15. R.Vicente, T. M. Ferreira, J.A. Raimundo, M. da Silva, Journal of Cultural Heritage 16, 1-14 (2015)

16. R. Douglas-Jones, J. J. Hughes, S. Jones, T. Yarrow, Journal of Cultural Heritage 21, 823-833(2016) 
17. All-Russian society of protection of monuments of history and culture. Saint-Petersburg city office. Analysis of materials of the landscape-visual analysis of the possible impact on the historic centre of Saint Petersburg, high-rise structures design of public and business complex Okhta-Center, (2009)

18. O.Risbol, C.Briese, M.Doneus, A.Nesbakken, Journal of Cultural Heritage 16, 202-209 (2015)

19. N. Othman, N. Mohamed, M. H. Ariffin, M. A. Waliyuddin A. Razak, Procedia - Social and Behavioral Sciences 170, 442-451 (2015)

20. M. Pazhouhanfar, M. Kamal M.S., Urban Forestry \& Urban Greening 13(1), 145-151 (2014)

21. S. Garré, S. Meeus, H. Gulinck, Landscape and Urban Planning 92(2), 125-135 (2009) 